\title{
Evidence of inadequate investigation and treatment of patients with heart failure
}

\author{
Karen W Clarke, David Gray, John R Hampton
}

\begin{abstract}
Objective-To determine the referral rates to hospital and level of investigation of patients with heart failure, and to assess whether they are receiving optimum management.

Design-A retrospective survey.

Setting-Nottingham Health District.

Patients-505 patients receiving loop diuretic treatment prescribed by their general practitioner.

Main outcome measures-Referral to hospital as an inpatient or outpatient for assessment of assumed cardiac failure; investigations-electrocardiography, chest radiography, and echocardiography; treatment with angiotensin converting enzyme inhibitors.

Results-Only $56 \%$ of patients prescribed loop diuretics fulfilled the diagnostic criteria for heart failure. Of these, $74 \%$ had been referred to hospital, of whom $80 \%$ had had an electrocardiograph, $75 \%$ a chest radiograph, but only $31 \%$ an echocardiogram. Only $17 \%$ of patients with heart failure were being treated with angiotensin converting enzyme inhibitors in conjunction with loop diuretics.

Conclusions-Patients with heart failure in the Nottingham Health District are not being adequately investigated or receiving the optimum treatment.
\end{abstract}

(Br Heart f 1994;71:584-587)

Heart failure affects between $0.4 \%$ and $0.8 \%$ of the general population in the United Kingdom. ${ }^{12}$ We estimate that the prevalence of heart failure is more likely to be in the region of $1.5 \%$ (unpublished data), this is compatible with data from the United States ${ }^{3}$ and makes the condition as common in Nottingham as ischaemic heart disease. ${ }^{4}$ The treatment of chronic heart failure uses a considerable proportion of National Health Service resources, ${ }^{5}$ and $5 \%$ of all adult hospital admissions are due to heart failure ${ }^{6}$ with each patient staying in hospital for between eight $^{5}$ and 17 days. $^{6}$

There is now good evidence to suggest that all patients with symptomatic heart failure and impaired left ventricular systolic function will benefit from treatment with an angiotensin converting enzyme inhibitor ${ }^{78}$ and therefore all patients with assumed heart failure should have an echocardiogram and treatment with an angiotensin converting enzyme inhibitor if tolerated.

In allocating resources it is important to know not only the prevalence of a condition but also the demand that is placed or might be placed on specialist services.

Recent evidence suggests that general practitioners rather than the hospital services treat most of these patients, ${ }^{2}$ and we therefore decided to investigate how patients with heart failure in our health district are treated and to determine what use they make of local cardiological services and whether they are receiving optimum treatment.

It is likely that most patients with symptomatic heart failure will be prescribed a loop diuretic either alone or in combination with other treatment such as an angiotensin converting enzyme inhibitor; patients prescribed loop diuretics by their general practitioner were therefore chosen as our study population.

\section{Patients and methods} METHODS

General practices were selected at random from the Nottinghamshire Family Health Services Authority list, and were asked if their practice computers were able to produce a list of all patients on loop diuretics. Six general practices from the 20 practices initially selected were able to produce such a list and agreed to participate in the study. The notes of 505 patients so identified were then examined in the general practitioners' surgeries by one of the authors (KWC). The patients' sex, age at diagnosis, symptoms and signs, investigations carried out, and current medication were all recorded. Five of the practices were urban and the other semirural. The practices had a total of 22000 patients aged over 30 registered with them, and the age sex breakdown of these practices was similar to that of Nottinghamshire as a whole.

The clinical diagnosis of heart failure poses problems, and whereas several standard sets of criteria have been developed to assist in the diagnosis ${ }^{10}$ these involve clinical examination of the patient. For the purposes of our study, patients were judged to have had diuretics prescribed for heart failure if they satisfied any one of the following criteria. 
Data on patients

\begin{tabular}{lll}
\hline & $\begin{array}{c}\text { Median age } \\
(y r)\end{array}$ & $F / M$ \\
\hline $\begin{array}{l}\text { All patients on diuretics } \\
(\mathrm{n}=505)\end{array}$ & 73 & $60 / 40$ \\
$\begin{array}{l}\text { Patients with heart failure } \\
(\mathrm{n}=281)\end{array}$ & 76 & $47 / 53$ \\
$\begin{array}{l}\text { Patients referred to hospital } \\
(\mathrm{n}=230)\end{array}$ & 71 & $48 / 52$ \\
$\begin{array}{l}\text { Patients treated by general practitioner } \\
(\mathrm{n}=275)\end{array}$ & 80 & $70 / 30$ \\
\hline
\end{tabular}

(a) Exertional dyspnoea, orthopnoea, or paroxysmal nocturnal dyspnoea relieved by diuretic treatment.

(b) Dyspnoea with signs of a raised jugular venous pressure, or a third heart sound, or ankle oedema, or basal crepitations.

(c) Dyspnoea with an increased cardiothoracic ratio, upper lobe blood diversion, or frank pulmonary oedema on a chest radiograph.

(d) Dyspnoea with echocardiographic evidence of left ventricular dysfunction or impaired left ventricular contraction apparent during a contrast ventriculogram.

\section{Results}

PATIENT DEMOGRAPHY

Of the 505 patients $300(60 \%)$ were female and $205(40 \%)$ were male. The median (range) age at the time of starting diuretics was 73 (0-96) years including those with congenital heart disease $(76 \%$ of patients were $\geqslant 65$ when they were first prescribed frusemide).
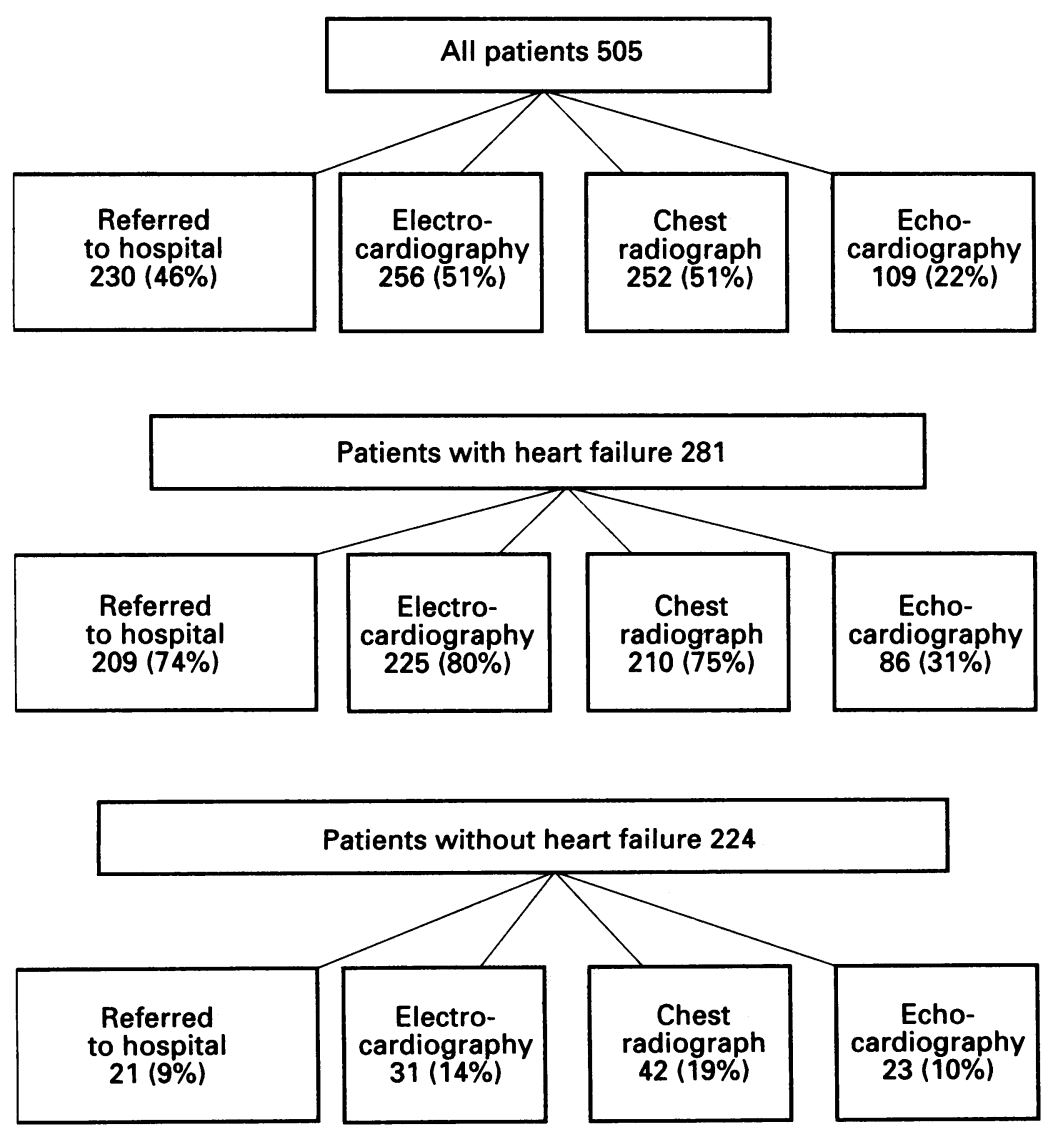

Investigations of patients
PATIENTS PRESCRIBED DIURETICS FOR HEART FAILURE

Of the 505 patients being treated with diuretics by their general practitioner, $281(55 \cdot 6 \%)$ fulfilled our diagnostic criteria for heart failure. The other main reasons for prescribing frusemide were hypertension $(16 \%)$ and ankle oedema of unknown cause (11\%).

\section{HOSPITAL REFERRAL}

Of the $\mathbf{5 0 5}$ patients on diuretic treatment 230 (46\%) were referred to one of two teaching hospitals in the city for investigation of presumed heart failure. Half (52\%) were admitted as emergency cases and half (48\%) were referred to the medical out patient clinics.

The table shows that the patients not referred to hospital tended to be elderly (median age 80 years) and female $(70 \%$ of the patients not referred to hospital). Among patients not referred, $26 \%$ had ankle oedema as the only indication for diuretic prescription and in $11 \%$ no obvious symptoms were recorded in their notes. By contrast, ankle oedema was the sole symptom in only one patient who was referred to hospital.

Two general practitioners referred $38 \%$ of their patients taking loop diuretics, two referred $44 \%$, and the others $52 \%$ and $55 \%$.

Of the 281 patients who fulfilled our diagnostic criteria for heart failure $209(74 \%)$ had been referred to hospital; 115 (55\%) had been admitted acutely. These 209 patients actually accounted for $91 \%$ of the total hospital referrals; the remaining 72 patients fulfilled our diagnostic criteria for heart failure but the general practitioners did not consider it necessary to refer them for specialist advice.

\section{INVESTIGATIONS}

Electrocardiograph

Of the 505 patients 256 (51\%) had had an electrocardiograph; of these $24 \%$ had been arranged by the general practitioner.

Of the 281 patients with evidence of heart failure $225(80 \%)$ had had an electrocardiograph, of which $19 \%$ had been arranged by the general practitioner. These accounted for $88 \%$ of the total electrocardiographs performed.

\section{Chest radiograph}

Of the 505 patients $252(51 \%)$ had had a chest radiograph. Of these $189(73 \%)$ were abnormal in keeping with heart failure.

Of those patients who fulfilled our criteria for heart failure $210(75 \%)$ had had a chest radiograph; 27 of these were normal. These 210 patients accounted for $83 \%$ of all the radiographs performed.

Echocardiography and cardiac catheterisation Of the 505 patients 109 (22\%) had had an echocardiogram. Of these $95(87 \%)$ were abnormal with either valvar heart disease or evidence of left ventricular dysfunction.

Of the 281 patients who fulfilled diagnostic criteria for heart failure $86(31 \%)$ had had an echocardiogram. Only six of these echocardiograms were normal; $63 \%$ had evidence of 
left ventricular dysfunction, $20 \%$ mitral valve disease, $8 \%$ aortic valve disease, and $2 \%$ congenital heart disease.

A total of seven (1.3\%) patients had had a contrast ventriculogram (as part of the investigation of ischaemic heart disease) and two of these showed impaired left ventricular contraction (figure).

\section{TREATMENT}

Eighty (16\%) of the 505 patients were prescribed angiotensin converting enzyme inhibitors in combination with loop diuretics. Of these 33 were being treated for hypertension.

Of the 281 patients with heart failure 47 $(17 \%)$ were also prescribed angiotensin converting enzyme inhibitors. Of these patients 44 had had treatment started by hospital physicians, and all three patients who had treatment initiated by the general practitioner were under the care of the same general practitioner.

\section{Discussion}

We have shown that $75 \%$ of patients whom the general practitioners are treating with loop diuretics for heart failure have been referred to hospital either as out patients or as acute admissions. The remaining $25 \%$ of patients who fulfilled our diagnostic criteria for heart failure were being treated by the general practitioner alone. Forty per cent of the patients with heart failure have been seen as in-patients at least once. Other studies suggest that $7 \%$ of all medical consultations for heart failure involve an in-patient stay, ${ }^{2}$ and that there are 14 general practitioner visits for each general medical in patient stay. If the 115 patients who had been admitted in our study had only done so on one occasion each, this would mean that they had been seen by the general practitioners in excess of 1600 times in the same time period. This may be the case, but it would seem to suggest that more of our patients are being referred for specialist opinion.

Most of the investigations carried out have been by hospital practitioners-general practitioners had arranged less than one quarter of the electrocardiographs, and about $10 \%$ of the chest radiographs. Despite the fact that $74 \%$ of patients with heart failure have been seen at the hospital, only one third have had an echocardiogram. The reason for this is not clear, although it may simply be that many patients are not seen by cardiologists. It could be suggested that all patients with heart failure should have an echocardiogram not only to confirm the diagnosis, but also to exclude valvar heart disease as an underlying cause, and as a possible contraindication to angiotensin inhibitor treatment.

The clinical diagnosis of heart failure is not necessarily accurate ${ }^{11}$ and there is evidence that only $50 \%$ of patients being treated for heart failure have echocardiographic evidence of left ventricular systolic dysfunction. ${ }^{2}$ In our sample, we have shown a much higher rate of abnormal findings on echocardiography, and two thirds of the patients who fulfil diagnostic criteria for heart failure have evidence of impaired left ventricular function.

Not only are more of the patients in our study referred to hospital, but a higher percentage of them have abnormal echocardiograms in comparison with other studies. ${ }^{2}$ It is important to note, however, that many of our patients are still not being fully investigated. It is also noteworthy that the patients not referred to hospital were older than those who were referred, and this may be influencing referral patterns and investigation.

Perhaps the most important aspect of our study is that few patients with clinical evidence of heart failure, and indeed with echocardiographic evidence of left ventricular dysfunction, are being treated with angiotensin converting enzyme inhibitors. Both the CONSENSUS and SOLVD studies have shown that symptomatic patients with heart failure benefit in terms of quality of life from such treatment. ${ }^{7}$ There are 234 patients in our cohort who fulfil our diagnostic criteria for heart failure who are not receiving angiotensin converting enzyme inhibition. Whereas many of these patients have not had an echocardiogram, 26 of them have documented evidence of impaired left ventricular function and are therefore not receiving the optimum treatment. There are also no good reasons why the more elderly patients should not receive angiotensin converting enzyme inhibitor treatment, and we should be investigating these people as thoroughly as others.

We have shown that in Nottingham a large proportion of patients with heart failure are seen at the hospital. Most of them are neither being fully investigated nor necessarily receiving the best treatment. At present the low investigation rate must in part be due to the hospital physicians. It should be remembered, however, that general practitioners could be more involved in appropriate management; we are at present evaluating the demand for an "open access" echocardiography service in our hospital. Not all patients need to have angiotensin converting enzyme inhibitors initiated in hospital, ${ }^{12}$ but can safely have them started in the community.

It seems that there is still some way to go in adequately treating patients with heart failure both in the community and after referral to hospital. We recommend that every patient who is clinically thought to have heart failure has an echocardiogram, and we are encouraging local general practitioners to use our "open access" echocardiography service and to treat patients with angiotensin converting enzyme inhibitors themselves when there are no contraindications to do so.

We are grateful to the general practitioners of Nottingham without whose assistance this study would not have been possible.

KWC is the Prophit-Rosser Fellow of the Royal College of Physicians. 
1 Parameshwar J, Schackell MM, Richardson A, PooleWilson PA, Sutton GC. Prevalence of heart failure in three general practices in north west London. $\mathrm{Br} \mathcal{F}$ Gen Pract 1992;42:287-9.

2 Wheeldon NM, MacDonald TM, Flucker CJ McKendrick AD, McDevitt DG, Struthers AD. An echocardiographic study of chronic heart failure in the community. Q F Med 1993;86:17-23.

3 Schocken DD, Arrieta MI, Leaverton PE, Ross EA. Prevalence and mortality rate of congestive heart failure in the United States 7 Am Coll Cardiol 1992:20:301-6.

4 Cannon PJ, Stockley IH, Connell PA, Garner ST, Hampton JR. Prevalence of angina as assessed by a sur-

McMurray J, Dargie H. Coronary heart disease. BMF 1991;303:1546.

6 Parameshwar J, Poole-Wilson PA, Sutton GC. Heart failure in a district general hospital. $\mathcal{F}$ Coll Physicians

7 The CONSENSUS Trial Study Group. Effects of enalapril on mortality in severe congestive failure: results of the cooperative North Scandinavian enalapri survival study (CONSENSUS). N Engl f Med 1987; 316:1429-35.

8 The SOLVD Investigators. Effect of enalapril on survival in patients with reduced left ventricular ejection fractions and congestive heart failure. $N$ Engl $f \mathrm{Med}$ 1991;325:293-302.

9 McKee PA, Castelli WP, McNamara WB. The natural history of congestive heart failure: the Framingham study. $N$ Engl $\mathcal{F}$ Med 1971;285:1441-6.

10 Carlson KJ, Lee DC-S, Goroll AH, Leahy M, Johnson RA. An analysis of physicians' reasons for prescribing digitalis therapy in out patients. $f$ Chron Dis 1985; 38:733-9.

11 Remes J Miettinen $\mathrm{H}$, Reunanen A, Pyorala $\mathrm{K}$ Validity of clinical diagnosis of heart failure in primary health care. Eur Heart 7 1991;12:315-21.

12 British National Formulary. London: BMA and Royal Pharmaceutical Society of Great Britain. 1993;25:87. 